Stuck in the suburbs? Socio-spatial exclusion of migrants in Shanghai

Jie Shen*

School of Social Development and Public Policy, Fudan University, Shanghai, 200433, China, shenj@fudan.edu.cn

* Corresponding Author

(C) 2016. This manuscript version is made available under the Elsevier user license http://www.elsevier.com/open-access/userlicense/1.0/ 


\title{
Stuck in the suburbs? Socio-spatial exclusion of migrants in
}

\section{Shanghai}

\begin{abstract}
Migrants' residential location plays a critical role in their social integration process. In China, large numbers of migrants are coming to the major cities due to the opportunities they offer, and most of them have to be settled in the disadvantaged urban periphery. By examining the place effects of suburban residence on the incorporation of migrants into cities, this paper contributes to the literature on understanding the socio-spatial exclusion of migrants. Drawing on a survey undertaken in Shanghai, it is found that, after controlling for the effects of individual characteristics, migrants living in the suburbs not only earn less than their counterparts in the central city, but are also less likely to construct inter-group and diverse social ties to aid future prospects. To make matters worse, they have little chance of moving to the central locations where there are more resources, and instead are likely to be trapped in the suburbs.
\end{abstract}

Keywords: migrants; residential location; segregation; suburbs; China

\section{Introduction}

China has experienced rapid urbanization during the past three decades. The influx of rural-to-urban migrants into Chinese cities had reached more than 270 million persons by 2014 (NBSC, 2015). This group, however, is known as the floating population (liudong renkou), because they are not entitled to the same legal rights as permanent urban residents and are treated as "internal aliens" in the cities (Zhang, 2001: 23). With regard to their residence, they tend to concentrate at the urban periphery, particularly in urban villages, construction sites, or industrial factory dormitories (Wu, 2008; Wang, 2010). 
While there is a large body of literature on rural-to-urban migrants in China concerning the effects of the hukou system, labour market segmentation, migration strategies, and their marginalization in the cities etc. (Chan, 2009; Fan, 2002; Fan et al., 2011; Solinger, 1999), only recently have scholars turned to examine migrants' housing experiences and social-spatial exclusion in cities (Wu, 2008; Wang et al., 2010; Huang and Tao, 2014). Many studies have focused on the neighbourhood effects of migrants' enclaves and the implications for their incorporation into the host society (Ma and Xiang 1998; Zhang, 2001; Liu et al., 2014). However, little has been done to investigate the role of migrants' residential location in their integration into the cities. The latter issue, however, is becoming increasingly important, because the recent massive demolition of urban villages in the inner suburban area has pushed migrants farther away. Consequently, as recently noted by Wu et al. (2013), migrants in remote suburban neighbourhoods might suffer from not having access to jobs and public services, thus making it even more difficult for the migrants to survive.

In the West, understanding immigrants' residential location is an important element in understanding their assimilation process. Among other issues, there has long been widespread concern over the social implication of the suburbs being their residential location. Earlier spatial assimilation models based on immigrants' experiences in the US considered immigrants' relocation to the suburbs as an indication of their structural assimilation (Massey, 1985; Waren, 2013). However, recent evidence has indicated that immigrants' spatial proximity to the majority group does not necessarily lead to integration, and residents of the suburban ghettoes face 
more barriers to much needed services than do those in central cities (Logan and Alba, 1993; Murphy, 2007; Murphy and Wallace, 2010).

Drawing on a survey undertaken in Shanghai, this study aims to explore whether migrants' marginal positions in the host society are further reinforced by the constraints of life in the urban periphery. While not denying the positive role of suburbs in the supply of low-cost housing, it is argued that peripheral locations may further reinforce migrants' marginal position in the city in the long run.

The paper is organized as follows. Based on urban experiences from both Western and developing countries, the next section reviews the literature in the field of (im)migrants and suburbanization. Then, the residential settlement patterns of migrants in urban China are summarized, and the explanatory framework is developed. Next, the data collection and analysis methods are introduced. The empirical findings from the Shanghai survey are discussed in the following section. Finally, the main findings are concluded, and policy recommendations are proposed.

\section{Literature review: (im)migrants and the suburbs}

There has been extensive research on (im)migrants' settlement patterns in the field of urban studies. Ecologists from the Chicago School claimed that, while newly arrived immigrants usually concentrate in neighbourhoods in the central city, later generations would relocate and disperse to the suburbs (Burgess 1925:56). These observations were later theorized by Massey (1985) as the spatial assimilation model. There is also empirical evidence that suburbanization was a key step in the assimilation of immigrants who arrived in the US in the early twentieth century (e.g. 
Massey and Denton 1987; Alba et al. 1997; Iceland and Nelson, 2008).

The spatial-assimilation model, however, has been widely challenged since the 1990s. Logan and Alba (1993) proposed an alternative model, known as the place stratification model, to depict the different impacts of suburbanization on different races. It is argued that, because the mechanisms of structural discrimination persist, minority groups might not able to translate their individual-level characteristics, such as income, education, etc., into upward residential mobility. As a result, when they move to the suburbs, they only sort themselves into suburban communities with a low status.

In the US, for example, the barrier to suburban residence was significantly reduced, and many immigrants began to settle in suburban communities immediately upon arriving in the US (Alba et al. 1999). However, instead of dispersing into white native-born communities, immigrants living in the suburbs have continued to concentrate in ethnic neighbourhoods (Logan et al., 2004). Li $(1998,2009)$ proposed a new model of ethnic settlement, the "ethnoburb", to capture the emerging suburban ethnic clusters of residential areas and business districts. Moreover, recent studies have indicated that minority immigrants are even more spatially segregated in their new suburban destinations (Lichter et al., 2012). Suburban residence does not necessarily lead to improvements in quality of life and could even make the immigrant groups more disadvantaged than those in the central city (Murphy, 2007; Murphy and Wallace, 2010).

The housing experiences of migrants in the Global South do not follow the 
uniform pattern found in the Global North. In many developing countries, cities are experiencing the process of urbanisation. Rapid urban expansion reveals a different suburban landscape with high population densities and mixed urban and rural activities. While searching for job opportunities in the cities, urban-to-rural and stepwise migrants concentrate at the urban fringe, which often leads to massive squatter settlements (Gilbert and Crankshaw, 1999; Davis, 2006). Turner (1968) suggested that, in fact, there are two stages of settlement for these migrants. New migrants usually live in rented accommodation in central locations near their jobs. However, later, they tend to move to the urban edge and build informal shanties of their own, a relocation process which indicates their permanent settlement in the destination city.

Recently, high-profile projects, such as gated communities, industrial parks, and shopping malls, have begun to emerge in the urban peripheral areas in these countries. However, most of them are built as private realms and scarcely contribute to improving the overall local economy and to softening social inequality. For instance, by examining the widespread development of gated communities in one suburban municipality in Argentina, Roitman and Phelps (2011) illustrated a typical dualistic process of suburbanisation in contemporary developing countries: poverty and exclusion in the suburbs actually increase when wealthy people arrive.

Therefore, in both developed and developing countries, (im)migrants living in the suburbs might face more barriers to integration. Then how might peripheral locations influence the incorporation of new comers into their destination city? There 
are several potential mechanisms that may give rise to the disadvantages experienced by suburban migrants. The most common explanation rests on the lack of good job opportunities near (im)migrants' residences. In the US, the decentralisation of lowskill jobs in manufacturing, construction, and services is prominent, and low-wage and often dead-end jobs dominate the labour market of fast-growing suburban nodes (Kneebone, 2009; Raphael and Stoll, 2010). This provides few routes for immigrants to become upwardly mobile (Lichter et al., 2010).

The second explanation concerns (im)migrants' constrained mobility and accessibility on the urban edge. Empirical evidence shows that (im)migrants' economic opportunities and social participation are reduced due to their lack of access to public facilities and services (Foth et al., 2013; Bose, 2014). Poor suburban communities have far less access to social service resources due to a lack of adequate provision (Allard, 2004). As the private provision of public services is increasingly dominant in the suburbs, this problem can become more severe (McKenzie, 1994, 2005). Moreover, because (im)migrants rely heavily on public transport, an inadequate public transportation infrastructure and a lack of car ownership could impose greater restrictions on them in the automobile-dependent suburbs.

Finally, spatial segregation can be worse in the suburbs. To date, no consensus has been reached on the effects of spatial segregation on (im)migrants' integration. Some studies have stressed the social and cultural capital (im)migrants could acquire in their neighbourhoods (Portes and Jensen, 1987, 1989). Others, however, have found that persistent segregation actually delays the long-term assimilation of 
immigrants and hence is a threat to social cohesion (Nee et al., 1994; Xie and Gough, 2011). Empirical studies have shown that limited opportunities for exposure to members of the majority ethnic groups in the neighbourhoods are associated with higher risks of poverty and unemployment (Galster et al., 1999; Feng et al., 2014). Such neighbourhoods' poor social networks and bad reputation are also important factors leading to negative outcomes for their residents (Musterd and Andersson, 2005; Permentier et al., 2007). These problems can be more apparent in isolated and lowdensity suburbs as residents will be less frequently exposed to each other compared to those living in densely populated central areas.

\section{The spatial entrapment of migrants in Chinese cities}

Migrants' residential spatial patterns in China are more similar to those found in other developing countries. Migrants tend to concentrate in the urban periphery instead of in central areas $(\mathrm{Wu}, 2008)$. They now constitute a major source of rapid population growth in the suburbs (Shen and $\mathrm{Wu}, 2013$ ). Moreover, they are often spatially clustered through their place of origin in certain types of neighbourhoods, creating migrant enclaves on the urban edge (Ma and Xiang 1998; Zhang 2001). However, in contrast to their counterparts who live in self-help housing on the urban edge in many other developing countries (Turner, 1976), suburban migrants in China are mostly living in employer-provided dormitories and private rental housing (Huang and Rao, 2014).

On the supply side, in contrast to Western "suburbia", the term "jiaoqu (literally, suburb)" in the Chinese context refers to the periphery of the city proper or built-up 
area mainly in a geographical sense rather than a distinctive type of residence. Before the early 1980s, the suburbs were underdeveloped and by no means attractive residential locations, being largely dominated by rural areas and a few small-scale industrial satellite towns. After the economic reform, Chinese cities immediately experienced rapid suburbanization due to the establishment of a land market and consequent changes to land use (Zhou and Ma, 2000). However, central areas have remained prosperous and are the preferred place to live and work (Wang and $\mathrm{Li}$, 2004). Due to the lack of public services and facilities, housing prices in the suburbs are relatively low when compared to those in central areas.

More importantly, there are usually large numbers of low-cost private rental houses on the outskirts of the city. Both formal and informal suburban developments provide low-cost rental housing for migrants. On the one hand, municipal governments expropriate farmland at a very low price and lease the land for real estate development. Such projects are carefully designed and packaged to make the suburbs seem an attractive place to live. These estates remain beyond the budget of most migrants, but a large proportion of properties in the suburbs are bought simply as investment and are then leased out via the rental market. A new type of living form for migrants known as qunzu (literally, co-renting), i.e. an apartment with two to three bedrooms that is divided and leased to several migrant families separately, has become widespread in the suburbs of many large cities.

On the other hand, any market transaction of collectively-owned farmland and villages is forbidden. Former villages have thus been engulfed by rapid urban 
expansion. Having no right to transfer the land for their own benefit, peasants build or extend their houses and rent them to migrants (Lin et al., 2011; Zhang, 2011). These "urban villages (chengzhongcun)" on the outskirts of cities have become a major source of low-cost private rental housing for migrants in cities (Wang et al., 2010).

On the demand side, to a large extent, the concentration of migrants on peripheral locations reflects the disadvantage they face in the local housing market, which is rooted in both their socioeconomic status, such as income and occupation, and the Chinese unique hukou-based institutional barrier (Wu, 2004). Most migrants are usually at the bottom of the urban socioeconomic and labour market strata (Solinger, 1999; Fan, 2002). Given that the price of commodity housing has risen exorbitantly in Chinese cities, it is almost impossible for migrants to buy their own homes, let alone pay for high-price estates in central locations. Moreover, migrants without local hukou are denied welfare benefits, such as affordable housing (Tao and $\mathrm{Xu}, 2007$; $\mathrm{Xu}$ et al., 2011). As a result, migrants have very limited housing options, living in either employer-provided housing or low-cost private rental housing.

Besides, settling down in the suburbs is also associated with the important role of hometown-based social networks in facilitating migration. More often than not, when migrants first come to the city, they receive social support in finding jobs or accommodation from earlier migrants from the same place of origin. They usually work in the same enterprises and live in the same neighbourhoods as their relatives or friends who arrived earlier. As a result, suburban migrant enclaves such as urban villages are usually their initial residential location (Ma and Xiang, 1998; Zhang, 
2001). So far, debates on the social implications of migrant enclaves are inconclusive. While policy makers usually view migrant neighbourhoods as overcrowded, chaotic and dangerous places, many scholars highlight the positive role of these neighbourhoods in China's urbanisation (Zhang et al., 2003; Liu et al., 2014).

However, a suburban residence does not indicate migrants' spatial assimilation as found in Western countries or permanent settlement in other developing countries. An earlier survey has shown that proximity to their workplace and the availability of low-cost housing are the primary reasons why migrants chose their current houses in the suburbs (Shen and Wu, 2013). Yet, although hometown-based social resources play a positive role in their adaptation to urban life on their arrival, their life chances may later be significantly restricted and their marginal role may be further reinforced by a constrained life in the suburbs.

First, living in migrant enclaves may limit their exposure to other groups and thus their opportunities to build inter-group social networks. Earlier research has demonstrated that those who have lived in migrant urban villages for a longer time are less likely to construct non-hometown-based or neighbourhood-based social ties (Liu et al., 2012). Second, since economic reform, Chinese cities have experienced the massive decentralization of manufacturing jobs (Zhou and Ma, 2000). Most of these jobs provide poor pay and prospects. Third, poor mobility and accessibility to quality public services and facilities further make it difficult for suburban migrants to reach opportunities for work, education, health care, social activities etc. Subsequently, with limited social resources and restricted job-search areas, migrants may have few 
opportunities for upward social mobility and instead remain trapped in the suburbs. The remainder of the paper aims to empirically examine the differences between migrants living in central and in suburban areas, and how residential location affects the incorporation of migrants.

\section{Data and Methods}

This research is based on a questionnaire survey distributed in Shanghai. Since economic reform, the city has witnessed a massive influx of migrants. By the end of 2013, the total number of migrants in Shanghai had reached 9.535 million, accounting for approximately $40 \%$ of its total population (SSB, 2014). The spatial distribution of migrants in Shanghai has experienced rapid suburbanization. While in the 1980s, a large proportion of migrants found their residence in central areas, the 1990s saw inner suburban areas (the 10-20-km band) become locations where migrants would concentrate (Wu, 2008). According to the 2010 census data, high concentrations of migrants are now found in outer suburban districts. The location quotient for the percentage of migrant population shows that, on average, Minhang, Fengxian, Jiading, Qingpu and Songjiang have a higher proportion of migrants than Shanghai, and all but Minhang are outer suburban districts (Figure 1). Among others, Jiading, Qingpu and Songjiang even have greater populations of migrants than of native citizens. In contrast, the central areas continue to be dominated by native residents, who account for $75 \%$ of their total population (Figure 2). 


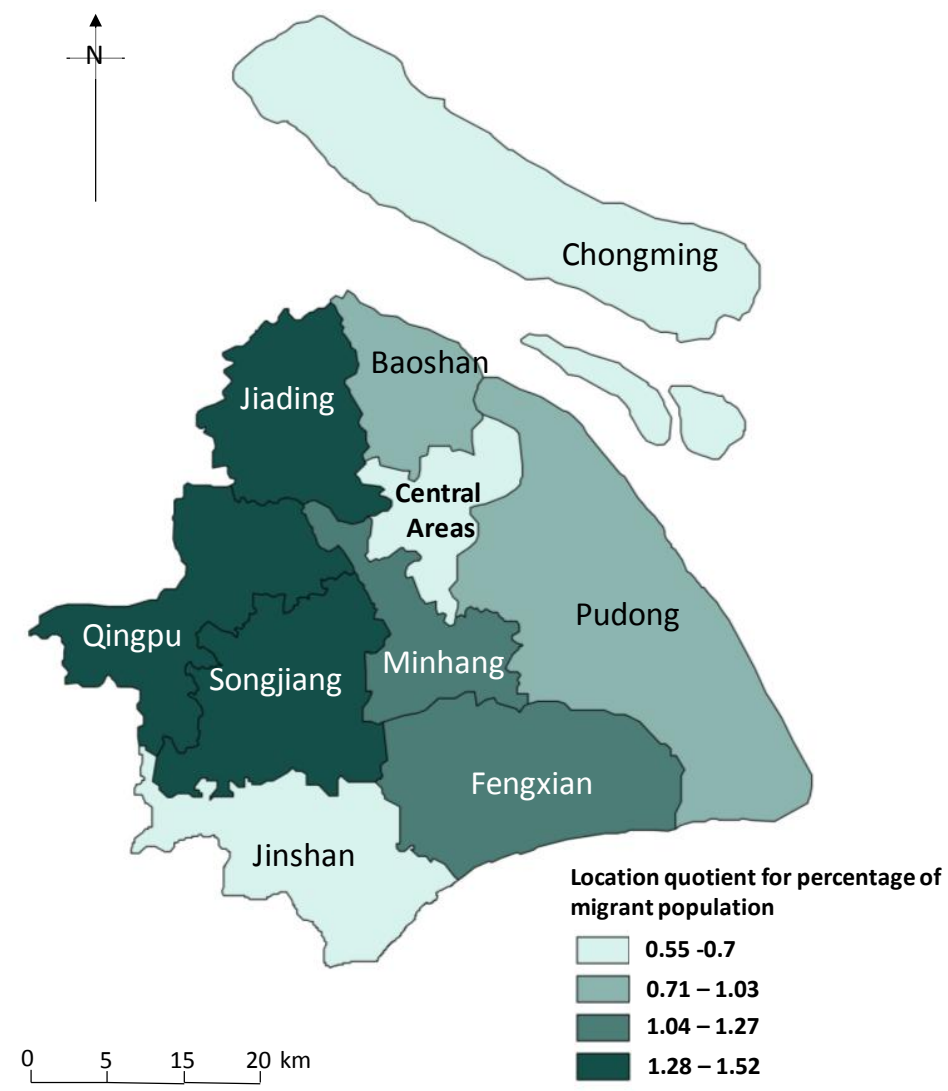

Figure 1 concentration of migrants in Shanghai by districts

Sources: 2000 and 2010 Shanghai census data

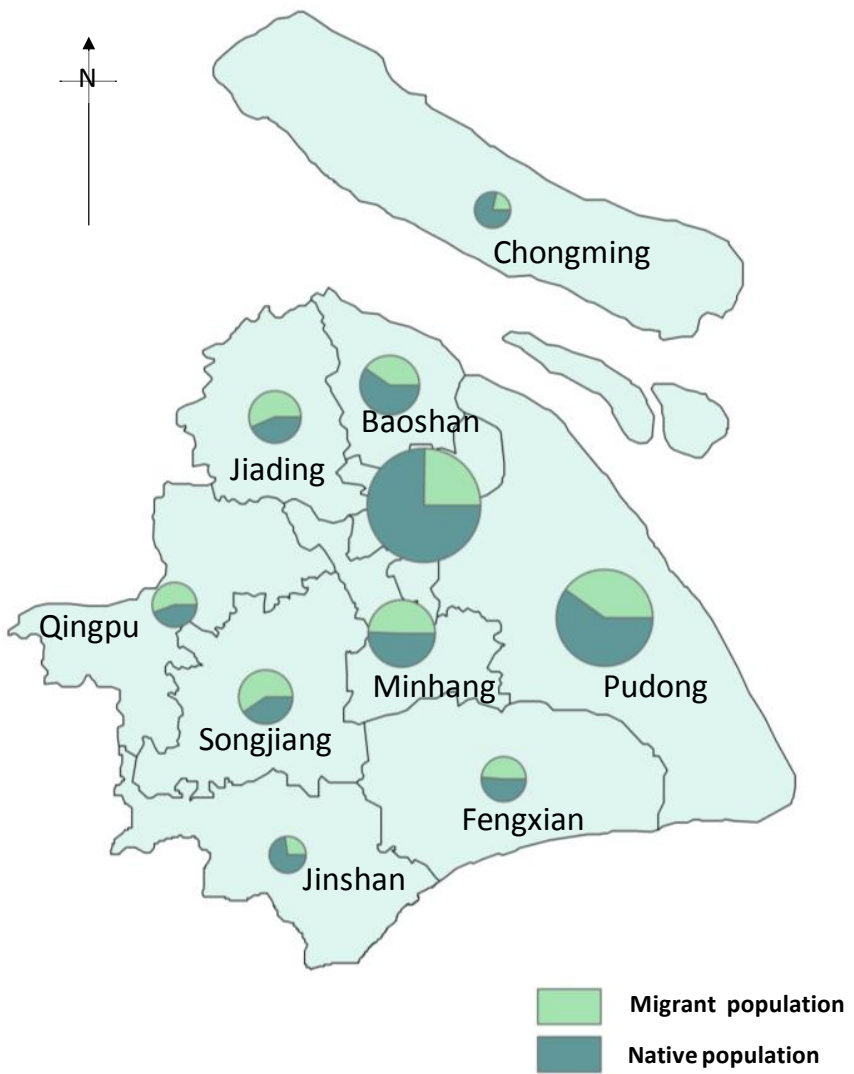

Figure 2 The ratio of migrant and native population by districts in Shanghai Sources: 2000 and 2010 Shanghai census data 
Spatial contexts in the central city and the suburbs are different for migrants. While the distribution of migrants is more dispersed in the central city, including to traditional lilong neighbourhoods, old work-unit neighbourhoods and newly-built commodity housing neighbourhoods, in the suburbs they are much more concentrated in urban villages and factory dormitories. For example, in suburban new towns, about $70 \%$ of the migrants resided in neighbourhoods with a proportion of migrants more than $60 \%$ (Wang and Yang, 2015). In the meantime, residents in the central city enjoy much better accessibility to resources than those in the suburbs. Recent studies have shown that, most neighbourhoods with high accessibility to jobs, health care facilities and schools locate within the inner ring of the city (Wu and Sun, 2015; Zhang, 2015; Wu et al, 2012).

The survey followed the principle of random sampling and adopted a multistage clustered sampling method. As Chongming Island remains largely dominated by rural areas and its population accounts for less than $3 \%$ of Shanghai's total population, it was excluded from the survey. First, all sub-districts (including both jiedao and zhen), except those on Chongming Island, were divided into three strata for stratified sampling: the inner city (within the inner ring road), the inner suburb (between the inner and outer ring road), and the outer suburb (outside the outer ring road). The number of sub-districts to be sampled in each stratum was in proportion to the size of the resident population in each area based on the 2010 population census data. In each stratum, sub-districts were sorted according to their per capita income and population density, and their de facto population was then adjusted according to their proportion 
of hukou population. This was to ensure that the structure of the sample was representative in these three terms. Then, the method of probability proportionate to size (PPS) sampling was used to select individual sub-districts. The final sample was drawn from 33 out of a total of 225 sub-districts from 12 districts in Shanghai. In each sub-district, one residential committee was randomly selected. Finally, within a chosen neighbourhood, an equal number of respondent households were randomly selected using a simple sampling method. The three-stage sampling technique ensured that the sample was representative of the inter-zone distribution of population.

The survey was undertaken from 20 July to 10 August 2013. Questionnaires were given to household heads, and most were completed immediately and collected by interviewers straight away. In total, 1420 valid questionnaires were collected, among which there were 295 migrant respondents. Notably, in this study, the term 'migrants' refers to those who were not born in Shanghai and had migrated to Shanghai from their place of origin. This allows for the examination of the role of hukou status in migrants' integration. In the sample, this migrant group is somewhat underrepresented. This is partly due to migrants' high rates of refusal and of noncontact. Nevertheless, because such levels of nonresponse can be regarded as random in this case, errors are tolerable. Table 1 compares migrants' educational and occupational attainments according to the 2010 Census and the survey. In both samples, the distribution of migrants' educational attainment is concentrated in junior and senior secondary education, while the distribution of their occupational attainment is concentrated in low-end service and industrial work. However, the 
survey sample has a higher proportion of migrants with higher education (college or above) and technician and staff jobs. This could be because the survey includes not only rural migrants, but also migrants with local hukou registration. In addition, the survey does not cover those living in factory dormitories. Given these two differences, the distribution of migrants' educational and occupational attainments in the survey sample is reasonable, and the survey sample is overall representative of the target group.

Table 1 Comparison of survey data and 2010 census statistics

\begin{tabular}{lrr}
\hline $\begin{array}{l}\text { Educational attainment } \\
(\%)\end{array}$ & $\begin{array}{r}\text { survey data } \\
(\mathrm{N}=259)\end{array}$ & $\begin{array}{r}\text { census data } \\
(\mathrm{N}=8589037)\end{array}$ \\
\hline No schooling & 1.16 & 1.82 \\
Primary school & 7.34 & 15.11 \\
Junior secondary & 36.68 & 52.75 \\
Senior secondary & 23.55 & 16.27 \\
college & 9.27 & 6.65 \\
university & 17.37 & 6.53 \\
graduate & 4.63 & 0.87 \\
& & \\
\hline Occupational attainment & survey data & census data \\
& $(\mathrm{N}=220)$ & $(\mathrm{N}=658820)$ \\
\hline manager or head & 3.64 & 3.82 \\
Technician & 23.18 & 8.31 \\
staff & 14.55 & 6.91 \\
Service worker & 40.00 & 34.01 \\
Industrial worker & 15.00 & 44.66 \\
other occupation & 3.64 & 2.28 \\
\hline
\end{tabular}

This study first gauges the importance of residential locations for migrants' integration. As the existing literature conceptualizes integration as a multidimensional process (Gordon, 1964; Alba and Nee, 1997), two key dimensions of integration are examined here: economic and social integration. Economic integration 
is achieved when the earnings of migrants are comparable to those of local natives with similar backgrounds (Chiswick, 1978; Duleep and Regets, 1999). As is conventional, because income is usually skewed, the log of household heads' monthly income is used as a measure of economic integration.

Social integration describes the process whereby migrants gradually adapt to social norms and values and participate in a broad range of social relationships in the host society (Brissette et al., 2000:54). Accordingly, the measure used in this study is inter-group friendship. Migrants who are more integrated are supposed to have friends outside their own group, while those who are less integrated are likely to have friends from the same place of origin as themselves. In the survey, respondents were asked where most of their friends came from, and the response categories were the same county or municipality, the same province, other provinces, Shanghai, and diverse places of origin. A dichotomous variable was then constructed to indicate whether a respondent's social relations were locally embedded (yes $=$ Shanghai natives and diverse place of origin $=1$, no $=$ other migrants $=0$ ).

Regression analysis was employed to test for the independent effects of residential location. In the analysis, place of residence was coded as one simple dichotomous variable indicating whether a respondent lived in the suburbs (including the inner suburbs and the outer suburbs) or the central city (suburbs $=1$, central city $=0$ ). Specific forms of actual regressions differ depending on the nature of the dependent. For economic integration (logged monthly income as the outcome variable), the ordinary least squares (OLS) linear regression was applied. For social 
integration (inter-group friendship as the outcome variable), the logit regression model was adopted.

Residential location was used as the central explanatory variable (suburbs $=1$; central city $=0$ ). Meanwhile, other variables that have been extensively studied in research on migrants' integration were also included to control for the effects of other mechanisms potentially influencing migrants' integration (Wu, 2012; Wang and Fan, 2013). The level of human capital was measured by whether a respondent held a university degree (yes $=1$, no $=0$ ), which is an important channel for migrants to establish their official residence in cities. Occupation was coded based on Chinese Standard Classification of Occupations and collapsed into three categories: blue collar, white collar, and others. Migrants usually have limited access to higher-status white collar jobs and tend to crowd into peripheral segments in the labour market, which could in turn reinforce their exclusion in both economic and social terms. Length of stay (number of years) may enhance migrants' exposure and acquaintance with the host society and was thus included to indicate the potential for integration. Hukou location and hukou classification, which are usually recognized as valid measures of migrants' integration, were used to represent the institutional factor. Finally, sociodemographic variables, i.e. age, gender, and marital status were also included to control for the effects of individual characteristics.

The study then used logistic regression analysis to examine further factors influencing the likelihood of migrants' spatial assimilation (i.e. moving to the central locations). Only respondents who reported intra-urban residential moves were 
included in the analysis. Their current residential location was used as the dependent variable (central city $=1$; suburbs $=0$ ). Their socioeconomic variables, economic and social integration variables, and previous residential location were all included as independent variables. If previous residential location had independent effects on migrants' residential moves, it would indicate migrants might be unable to translate their socioeconomic advancement into locational attainment, and vice versa.

\section{Results}

Table 2 compares the socioeconomic profiles and integration of migrants in central and suburban areas. ANOVA analysis and Pearson's chi-square test were conducted on the continuous variables and the categorical socioeconomic variables respectively. Overall, the two groups were shown to be significantly different in many aspects, with migrants living in the central city having the better socioeconomic status. Those in the central city were much more likely to hold a university degree; nearly half of the surveyed migrants there had a university degree. They also exhibited a much higher proportion engaging in white-collar jobs, i.e. as administrative managers, technicians, and office staff, but fewer numbers of industrial workers. In terms of hukou classification, the sample included $61.4 \%$ rural migrants and $38.6 \%$ urban migrants in total. More than half of the surveyed migrants in the central city were urban migrants, while two thirds of those in the suburbs came from rural areas. Although both groups had only a small number of individuals with Shanghai hukou, more migrants in the central city had managed to acquire one.

Integration of migrants in the central city was significantly better than that in the 
suburbs in both economic and social terms. The average income of the former group was about 1.8 times greater than that of the latter group $(14,500$ yuan versus 8,099 yuan). Meanwhile, migrants in the central areas were more likely to have local natives as their friends than were migrants in the suburbs (37.7\% versus $16.7 \%)$, although a large proportion in both groups reported that their friends came from the same province as themselves.

Table 2 Differences between migrants in the central city and the suburbs

\begin{tabular}{|c|c|c|c|}
\hline Attributes & Central City & Suburbs & statistic significance \\
\hline Age (Mean) & 40.8 & 36.9 & t-test, $\rho<0.5$ \\
\hline \multicolumn{4}{|l|}{ Gender } \\
\hline Male $(\%)$ & 55.70 & 64.6 & \\
\hline Female $(\%)$ & 44.30 & 34.4 & \\
\hline \multicolumn{4}{|l|}{ Marriage } \\
\hline Single(\%) & 16.4 & 16.2 & \\
\hline Married $(\%)$ & 83.6 & 83.8 & \\
\hline \multicolumn{4}{|l|}{ University Degree } \\
\hline None $(\%)$ & 50.8 & 74.2 & \multirow{2}{*}{$\chi^{2}$ test, $\rho<0.001$} \\
\hline $\operatorname{Hold}(\%)$ & 49.2 & 28.5 & \\
\hline \multicolumn{4}{|l|}{ Occupation } \\
\hline Manager or head (\%) & 8.2 & 1.5 & \multirow{7}{*}{$\chi 2$ test, $\rho<0.1$} \\
\hline Technician (\%) & 24.6 & 18.2 & \\
\hline Staff $(\%)$ & 14.8 & 11.6 & \\
\hline Service worker $(\%)$ & 36.1 & 33.8 & \\
\hline Industrial worker (\%) & 1.6 & 16.2 & \\
\hline Other occupation (\%) & 0.0 & 4.0 & \\
\hline Retired or Unemployed (\%) & 14.8 & 14.6 & \\
\hline \multicolumn{4}{|l|}{ Hukou Location } \\
\hline Local (\%) & 16.4 & 6.6 & \multirow{2}{*}{$\chi 2$ test, $\rho<0.5$} \\
\hline non-local $(\%)$ & 83.6 & 93.4 & \\
\hline \multicolumn{4}{|l|}{ Hukou Classification } \\
\hline $\operatorname{Rural}(\%)$ & 45.9 & 66.2 & \multirow{2}{*}{$\chi 2$ test, $\rho<0.5$} \\
\hline $\operatorname{Urban}(\%)$ & 54.1 & 33.8 & \\
\hline Family income (mean) & 14500 & 8099.49 & t-test, $\rho<0.001$ \\
\hline \multicolumn{4}{|l|}{ Origin of most friends } \\
\hline Shanghainese (\%) & 37.7 & 16.7 & \multirow{3}{*}{$\chi 2$ test, $\rho<0.01$} \\
\hline Migrants from same province (\%) & 59.0 & 81.3 & \\
\hline Diverse origin $(\%)$ & 3.3 & 2.0 & \\
\hline Total & 61 & 198 & \\
\hline
\end{tabular}


OLS linear regression was conducted to examine the independent effects of residential location on migrants' monthly income (Table 3). Because the dependent variable was logged monthly income, we could roughly interpret the estimated coefficient as the effect, in percentage, on earnings. The results confirm that socioeconomic attributes, including gender, higher education attainment, occupation, and the length of residence have important effects on the migrants' earnings. Male migrants earned $20 \%$ more than female migrants. Holding a university degree reflected the human capital of migrants and had a positive effect on their income, although the effect was not significant in the full model. In terms of occupation, the income of white-collar respondents was more than $30 \%$ higher than that of both bluecollar and retired and unemployed respondents. In the full model, there was also an effect of length of residence, as one extra year of residence in Shanghai increased migrants' earnings by $13 \%$. However, migrants' registration status, i.e. hukou location and hukou classification, was found to be not significant for migrants' earnings.

After controlling for other variables in the full model, living in the suburbs was found to have a negative and significant coefficient, indicating that on average, migrants living in the suburbs earned almost $18 \%$ less than those living in the central city, even when they have similar individual characteristics such as education and occupation. The place of residence variable remained in the forward linear regression model, which presented the determinants of migrants' earning returns, further confirming the independent effects of residential location. 
Table 3 OLS Linear Regression on logged monthly income

\begin{tabular}{|c|c|c|c|c|}
\hline \multirow{2}{*}{ Independent variables } & \multicolumn{2}{|c|}{ Full Model } & \multicolumn{2}{|c|}{ Forward Model } \\
\hline & $\mathrm{B}$ & SE & $\mathrm{B}$ & $\mathrm{SE}$ \\
\hline Age(years) & -0.128 & 0.002 & & \\
\hline Gender $($ Female $=1)$ & $-0.222 * * *$ & 0.034 & $-0.221 * * *$ & 0.033 \\
\hline Marriage(Married=1) & -0.033 & 0.043 & & \\
\hline University Degree $($ Hold=1) & 0.132 & 0.048 & $0.186 * *$ & 0.038 \\
\hline \multicolumn{5}{|l|}{ Occupation (White Collar=0) } \\
\hline Blue collar & $-0.342 * * *$ & 0.038 & $-0.321 * * *$ & 0.036 \\
\hline Others & -0.069 & 0.091 & & \\
\hline Unemployed and retired & $-0.311 * * *$ & 0.075 & $-0.351 * * *$ & 0.056 \\
\hline Length of Residence & $0.127 *$ & 0.003 & & \\
\hline $\begin{array}{l}\text { Hukou Location } \\
\text { (Local=1) }\end{array}$ & -0.105 & 0.059 & & \\
\hline $\begin{array}{l}\text { Hukou Classification } \\
(\text { Urban=1) }\end{array}$ & 0.11 & 0.044 & & \\
\hline $\begin{array}{l}\text { Residential Location } \\
(\text { Suburbs }=1)\end{array}$ & $-0.179 * *$ & 0.038 & $-0.161 * *$ & 0.037 \\
\hline Constant & $3.968 * * *$ & 0.093 & $3.866^{* * * *}$ & 0.046 \\
\hline $\mathrm{N}$ & 243 & & 243 & \\
\hline df & 11 & & 5 & \\
\hline $\mathrm{F}$ & $11.851 * * *$ & & $23.3 * * *$ & \\
\hline $\mathrm{R}^{2}$ & 0.361 & & 0.330 & \\
\hline
\end{tabular}

Table 4 shows the results of logistic regression on migrants' inter-group social ties. Among socioeconomic attributes, age and holding a university degree increased the likelihood of having an inter-group social network. As older migrants were more established, they were more likely to have local social ties. Holding a university degree increased the odds of having an inter-group friendship by 3.5 times. Meanwhile, as length of stay in Shanghai enhanced the exposure to the host society, it also had positive effects on migrants' social integration. One extra year of residence doubled the odds of having friends from Shanghai and other places. Interestingly, compared to rural migrants, urban migrants from other cities were much more likely 
to establish friendships with local natives and people from other places. Although this effect was not significant in the full model, the hukou classification variable remained in the forward regression model and was statistically significant. This implies that it is easier for urban residents to adapt to social life in the destination city.

Table 4 Logistic regression on inter-group friendship

\begin{tabular}{|c|c|c|c|c|c|c|}
\hline \multirow{2}{*}{ Independent variables } & \multicolumn{3}{|c|}{ Full Model } & \multicolumn{3}{|c|}{ Forward Model } \\
\hline & $\mathrm{B}$ & SE & $\exp (B)$ & $\mathrm{B}$ & SE & $\exp (\mathrm{B})$ \\
\hline Age(years) & $0.048 *$ & 0.02 & 1.049 & $0.043 * *$ & 0.017 & 1.044 \\
\hline Gender $($ Female $=1)$ & -0.022 & 0.38 & 0.978 & & & \\
\hline Marriage(Married=1) & -0.332 & 0.474 & 0.718 & & & \\
\hline University Degree $($ Hold=1) & $1.276^{* *}$ & 0.496 & 3.581 & $1.337 * *$ & 0.438 & 3.809 \\
\hline \multicolumn{7}{|l|}{ Occupation (White Collar $=0$ ) } \\
\hline Blue collar & -0.148 & 0.428 & 0.863 & & & \\
\hline Others & 1.074 & 1.02 & 2.926 & & & \\
\hline Unemployed and retired & -0.231 & 0.639 & 0.794 & & & \\
\hline Length of Residence & $0.067 * *$ & 0.03 & 1.07 & $0.068 *$ & 0.028 & 1.071 \\
\hline $\begin{array}{l}\text { Hukou Location } \\
(\text { Local=1) }\end{array}$ & 0.119 & 0.553 & 1.126 & & & \\
\hline $\begin{array}{l}\text { Hukou Classification } \\
(\text { Urban=1) }\end{array}$ & 0.774 & 0.449 & 2.169 & $0.812 *$ & 0.413 & 2.252 \\
\hline $\begin{array}{l}\text { Residential Location } \\
(\text { Suburbs }=1)\end{array}$ & $-0.735^{*}$ & 0.367 & 0.48 & $-0.698 *$ & 0.357 & 0.497 \\
\hline Constant & $-3.727 * * *$ & 1.05 & 0.024 & $-3.954 * * *$ & 0.798 & 0.019 \\
\hline $\mathrm{N}$ & 259 & & & 259 & & \\
\hline $\mathrm{df}$ & 11 & & & 4 & & \\
\hline$\chi^{2}$ & $58.264 * * *$ & & & $56.230 * * *$ & & \\
\hline$-2 \times$ log-likelihood & 226.826 & & & 228.860 & & \\
\hline Cox and Snell $\mathrm{R}^{2}$ & 0.201 & & & 0.195 & & \\
\hline Nagelkerke $\mathrm{R}^{2}$ & 0.302 & & & 0.292 & & \\
\hline
\end{tabular}

Notes: $* \rho<0.05 ; * * \rho<0.01 ; * * * \rho<0.001$

After controlling for the effects of individual attributes in the full model, residential location was again found to affect migrants' social integration. For the migrants in Shanghai, living in the suburbs made them two times less likely to have 
inter-group friendships. This variable also remained in the forward regression model, suggesting it is one of the determinants of having friends outside the migrant group.

In order to test the spatial entrapment of migrants in the suburbs, the residential mobility of migrants was further examined. As has been found in the existing literature, migrants in the survey showed a high level of residential mobility. About $49 \%$ of respondents reported that they had moved at least once, and about $45.7 \%$ of moves had taken place in the last three years. Among those who had never moved after coming to Shanghai, $70.5 \%$ migrants had settled in the suburbs, confirming that the suburbs are usually migrants' initial residential location. Moreover, only $7 \%$ of those who had previously lived in the suburbs had managed to move to the central city.

Table 5 shows the results of the logistic regression analysis, which tests the independent effects of previous residential location on migrants' subsequent location choices. Besides socio-economic attributes and hukou status as used above, monthly income and inter-group friendship were also included as measures of migrants' integration. The results suggest that, among those who move, married migrants are much more likely than single migrants to live in the central city. Local hukou also significantly increases the likelihood of moving to the central city. The level of earnings, which is an indicator of migrants' economic integration, has a positive effect on the chance of living in the central city. After controlling for other variables, previous residential location clearly plays an important role in migrants' subsequent residential location. Therefore, for migrants with similar socioeconomic backgrounds, 
those whose initial residence is located in the suburbs have much less of a chance of moving to the central city and are likely to be trapped in the suburbs.

Table 5 Logistic regress on migrants' residential location after recent moves

\begin{tabular}{|c|c|c|c|c|c|c|}
\hline & \multicolumn{3}{|c|}{ Full Model } & \multicolumn{3}{|c|}{ Forward Likelihood Model } \\
\hline & B & SE & $\operatorname{Exp}(B)$ & B & SE & $\operatorname{Exp}(B)$ \\
\hline Age(years) & 0.065 & 0.048 & 1.067 & & & \\
\hline Gender $($ Female $=1)$ & -0.608 & 0.881 & 0.545 & & & \\
\hline Marriage(Married=1) & $2.571^{*}$ & 1.168 & 13.08 & $2.01 *$ & 0.929 & 7.465 \\
\hline University Degree $($ Hold=1) & 0.84 & 1.032 & 2.316 & & & \\
\hline \multicolumn{7}{|l|}{ Occupation (White Collar=0) } \\
\hline Blue collar & 0.906 & 0.879 & 2.475 & & & \\
\hline Others & -0.861 & 1.864 & 0.423 & & & \\
\hline Length of Residence & -0.109 & 0.079 & 0.896 & & & \\
\hline $\begin{array}{l}\text { Hukou Location } \\
\text { (Local=1) }\end{array}$ & $2.823^{*}$ & 1.449 & 16.824 & $2.856^{*}$ & 1.184 & 17.39 \\
\hline $\begin{array}{l}\text { Hukou Classification } \\
(\text { Urban }=1)\end{array}$ & -0.068 & 1.002 & 0.934 & & & \\
\hline Inter-group friendship & & & & & & \\
\hline $\begin{array}{l}\text { Shanghai and diverse places of } \\
\text { origin=1) }\end{array}$ & 3.254 & 1.587 & 25.892 & & & \\
\hline Logged monthly income & $0.581^{*}$ & 0.796 & 1.788 & $2.784 *$ & 1.175 & 16.18 \\
\hline $\begin{array}{l}\text { Previous residential location } \\
\text { (suburbs }=1 \text { ) }\end{array}$ & $-3.889 * * *$ & 0.871 & 0.02 & $-3.505^{* * *}$ & 0.721 & 0.03 \\
\hline Constant & $-15.803 * * *$ & 6.742 & 0 & $-11.716 * * *$ & 4.542 & 0 \\
\hline $\mathrm{N}$ & 123 & & & 123 & & \\
\hline df & 12 & & & 3 & & \\
\hline$\chi^{2}$ & $50.780 * * *$ & & & $44.792 * * *$ & & \\
\hline$-2 \times \log$-likelihood & 64.757 & & & 70.745 & & \\
\hline Cox and Snell $\mathrm{R}^{2}$ & 0.338 & & & 0.305 & & \\
\hline Nagelkerke $\mathrm{R}^{2}$ & 0.555 & & & 0.501 & & \\
\hline
\end{tabular}

\section{Conclusion}

There is a growing literature on migrants' residential patterns in China ( $\mathrm{Wu}$, 2008; Wang et al., 2010; Huang and Tao, 2014). Earlier studies have found that migrants are disadvantaged in the urban housing market and usually concentrate in the 
suburbs. However, little is known about the place effects of suburban residence on migrants. In fact, residential location is not only a well-established indicator of people's socio-economic status, but is also a valued resource for them; it is therefore key to migrants' integration into the host society. In the Western literature, there is always debate about whether new comers to cities could achieve spatial assimilation or if structural sources of inequality always impede the improvement of migrants' spatial position (Massey, 1985; Logan and Alba, 1993). Based on a survey in Shanghai, this paper has empirically examined the relationship between migrants' integration and their suburban residential locations. While moving to the suburbs could reflect the spatial assimilation of (im)migrant groups in both Western and developing countries, suburban migrants may be spatially marginalized in disadvantaged suburban locations in China.

Specifically, there are three empirical findings. First, migrants living in the suburbs are earning less overall than their counterparts in the central city, even after controlling for demographic and socioeconomic characteristics. This indicates that economic returns to migrants' human capital are spatially unequal. Second, due to the relative lack of exposure to the host society in the suburbs, suburban migrants are less likely to have inter-group friendships or a diverse social network, which is of great significance in their social integration. Finally, while migrants show a high level of residential mobility, living in the suburbs reduces the likelihood of them moving to the central city or accessing more advantaged locations. Overall, suburban residence has long-term negative effects on both the socio-economic and spatial integration of 
migrants.

The interpretation of these results therefore highlights structural factors as the main mechanism leading to the social-spatial exclusion of migrants in the suburbs, lending support to the place stratification model. With the establishment of land and housing markets, Chinese cities have experienced massive spatial restructuring. While both the central city and its suburbs are flourishing, the former remains dominant in both administrative and functional terms. However, because migrants are largely excluded from the formal housing market, they are squeezed out of the central locations, where there are more resources, to marginal suburban communities, such as urban villages. Due to a relative lack of good job opportunities, poorer access to quality facilities and services, and more isolated neighbourhoods in the suburbs, their life chances are in turn further constrained.

The integration of migrants in the cities, which is regarded as a key factor to facilitate urbanization and social stability, has recently become the focus of inclusive urbanization. This study suggests that migrants concentrating in the relatively underdeveloped suburban locations have limited locational resources and opportunities for upward social mobility. Accordingly, beyond institutional adjustments, such as relaxing the hukou system, the improvement of the suburban infrastructure and the provision of good quality public services are also critical for the incorporation of migrants.

Another policy implication is associated with recent migrant housing policies, which focus on the demolition of urban villages and the construction of large-scale 
social housing communities in outer suburban areas. In fact, many of the first urban villages to be erased are in the inner suburbs of the city. They have played a positive role in providing affordable housing to rural migrants at locations closer to the urban economy. However, after these urban villages have been demolished, migrants may be displaced farther away, making it less likely for them to find a similar job to the one they had previously. Suburban large-scale social housing communities at remote locations are also at a risk of being marginalized and alienated. Therefore, to reserve the locational advantages for migrants, future policies of redevelopment should consider upgrading the migrants' current accommodation rather than opting for demolition and displacement.

\section{Reference}

Alba R.D., Nee V. (1997). Rethinking Assimilation Theory for a New Era of Immigration. International Migration Review, 31, 4,826-874

Alba, R. D., Logan, J. R., Stults, B. J. et al. (1999) Immigrant groups in the suburbs: a re-examination of suburbanization and spatial assimilation. American Sociological Review, 64(3), 446-460

Alba, R.D., Logan, J. R., and Crowder K. (1997). White Ethnic Neighborhoods and Assimilation: The Greater New York Region, 1980-1990. Social Forces, 75(3), 883-912

Allard, S. (2004). Access to Social Services: the Changing Urban Geography of Poverty and Service Provision. Metropolitan policy program, survey series. Washington, DC: The Brookings Institution 
Bose P. S. (2014). Refugees in Vermont: mobility and acculturation in a new immigrant destination. Journal of Transport Geography, 36,151-159

Brissette, I., Cohen S. and Seeman T. (2000). Measuring social integration and social networks. In S. Cohen, L.G. Underwood and B.H. Gottlieb (eds.), Social support measurement and intervention: a guide for health and social scientists, New York: Oxford University Press

Burgess, E.W. (1925). The Growth of the City: An Introduction to a Research Project, in R. E. Park, E. W. Burgess, and R. D. McKenzie (eds.), The City. Chicago, IL: University of Chicago Press, 47-62

Chan, K. W. 2009. The Chinese Hukou system at 50. Eurasian Geography and Economics, 50(2), $197-221$

Chiswick, B. R. (1978). The effect of Americanization on earnings of foreign-born men. Journal of Political Economy, 86, 897-921

Davis, M. (2006). Planet of Slums. New York: Verso

Duleep, H. O., Regets, M. C. (1999). Immigrants and human-capital investment. The American Economic Review, 89(2), 186-191

Fan C.C. (2002). The Elite, the Natives, and the Outsiders: Migration and Labor Market Segmentation in Urban China. Annals of the Association of American Geographers, 92(1), 103-12

Fan cc, Sun M., Zheng Si., (2011), Migration and split households: a comparison of sole, couple, and family migrants in Beijing, China. Environment and Planning A, 43(9), $2164-2185$

Feng X., Flowerdew R., and Feng Z. (2014). Does neighbourhood influence ethnic 
inequalities in economic activity? Findings from the ONS Longitudinal Study. Journal of Economic Geography, 15(1), 1-26

Foth, N., Manaugh, K., El-Geneidy, A. (2013). Towards equitable transit: examining transit accessibility and social need in Toronto, Canada, 1996-2006. Journal of Transport Geography, 29, 1-10

Galster, G.C., Metzger, K. and Waite, R. (1999). Neighbourhood opportunity structures and immigrants' socio-economic advancement. Journal of Housing Research, 10(1), 95-127

Gilbert, A., Crankshaw O. (1999). Comparing South African and Latin American experience: migration and housing mobility in Soweto. Urban Studies, 36 (13), $2375-2400$

Gordon, M. (1964). Assimilation in American Life. New York, NY: Oxford University Press

Huang Y., Tao R. (2014). Housing migrants in Chinese cities: current status and policy design. Environment and Planning C: Government and Policy, 33(3), 640-660

Iceland J., Nelson K.A. (2008). Hispanic segregation in metro America: exploring the multiple forms of spatial assimilation. American Sociological Review, 73(5), $741-765$

Kneebone, E. (2009). Job sprawl revisited: the changing geography of metropolitan employment. Metropolitan Policy Program, The Brookings Institution, Washington, DC

Li W (1998). Anatomy of a new ethnic settlement: The Chinese ethnoburb in Los 
Angeles. Urban Studies, 35(3), 479-501

Li W (2009). Ethnoburb: The New Ethnic Community in Urban America. Honolulu, HI: University of Hawaii Press

Lichter D. T., Parisi D., Taquino M.C., Grice S. M. (2010). Residential segregation in new Hispanic destinations: Cities, suburbs, and rural communities compared. Social Science Research, 39(2), 215-230

Lin Y., de Meulder B., and Wang S. (2011). Understanding the 'village in the city' in Guangzhou: Economic integration and development issue and their implications for the urban migrant. Urban Studies, 48(16), 3583-3598

Liu Y., Li Z and Breitung W (2012). The social networks of new-generation migrants in China's urbanized villages: A case study of Guangzhou. Habitat International 36(1), 192-200

Liu Y., Li Z., Liu Y. and Chen H. (2014). Growth of rural migrant enclaves in Guangzhou, China: Agency, everyday practice and social mobility. Urban Studies, 52(16), 3086-3105

Logan J. R., Stults B.J., Farley R. (2004). Segregation of minorities in the metropolis: two decades of change. Demography, 41(1), 1-22

Logan R.J. and Alba R.D. (1993). Locational Returns to Human Capital: Minority Access to Suburban Community Resources. Demography, 30(2), 243-268

Ma L.J.C and Xiang B. (1998). Native place, migration and the emergence of peasant enclaves in Beijing. The China Quarterly 155, 546-581

Massey D. and Denton N. (1987). Trends in Residential Segregation of Blacks, 
Hispanics, and Asians: 1970-1980. American Sociological Review 52(5), 802825

Massey, D. (1985). Ethnic Residential Segregation: A Theoretical Synthesis and Empirical Review. Sociology and Social Research, 69, 315-50

McKenzie, E. (1994). Privatopia: Homeowner Associations and the Rise of Residential Private Government. New Haven, CT and London, UK: Yale University Press

McKenzie, E. (2005). Constructing the Pomerium in Las Vegas: A case study of emerging trends in American gated communities. Housing Studies, 20(2), 187203

Murphy, A. K. (2007). The suburban ghetto: the legacy of Herbert Gans in understanding the experience of poverty in recently impoverished American suburbs. City \& Community, 6 (1), 21-37

Murphy, A. K. and Wallace D. (2010). Opportunities for making ends meet and upward mobility: differences in organizational deprivation across urban and suburban poor neighbourhoods. Social Science Quarterly, 91(5), 1164-1186

Musterd, S. and Andersson, R. (2005). Housing mix, social mix, and social opportunities, Urban Affairs Review, 40(6), 761-790

NBSC (National Bureau of Statistics of China), (2015). Report on the National monitoring Survey of migrant workers. http://www.stats.gov.cn/tjsj/zxfb/201504/t20150429_797821.html; accessed on 16 June 2015

Nee, V., Sanders, J. M. and Sernau, S. (1994). Job transitions in an immigrant metropolis: ethnic boundaries and the mixed economy, American Sociological 
Review, 59(6), 849-872

Permentier, M., van Ham, M. and Bolt, G. (2007). Behavioural responses to neighbourhood reputations, Journal of Housing and the Built Environment, 22(2), $199-213$

Portes, A. and Jensen, L. (1989). The enclave and the entrants: patterns of ethnic enterprise in Miami before and after Mariel. American Sociological Review, 54, 929-949

Portes, A., Jensen, L. (1987). What's an ethnic enclave? The case for conceptual clarity. American Sociological Review, 52, 768-771

Raphael S., Stoll M.A. (2010). Job Sprawl and the Suburbanization of Poverty. Metropolitan Policy Program, The Brookings Institution, Washington, DC

Roitman S., Phelps N.A. (2011). Do gates negate the city? Gated communities' contribution to the urbanization of suburbia in Pilar, Argentina. Urban Studies, 48 (16), 3487-3509

Shanghai Statistical Bureau (SSB) (2014). Shanghai Statistical Yearbook 2014. Official Web Site of Shanghai Statistical Bureau, http://www.stats-sh.gov.cn

Shen J., Wu F. (2013). Moving to the suburbs: demand-side driving forces of suburban growth in China. Environment and Planning A, 45(8), 1823-1844

Solinger D., (1999). Contesting Citizenship in Urban China: Peasant Migrants, the State, and the Logic of the Market. Los Angeles, CA: University of California Press

Tao, R. and Xu, Z. (2007). Urbanization, rural land system, and social security for migrants in China, Journal of Development Studies, 43(7), 1301-1320 
Turner, J. F. C. (1968). Housing patterns, settlement patterns, and urban development in modernizing countries. Journal of the American Planning Association, 34 (6), $354-63$

Turner, J. F. C. (1976) Housing by People: Towards Autonomy in Building Environments. London: Boyars

Wang Y., Wang Y., and Wu J. (2010). Housing migrant workers in rapidly urbanizing regions: A study of the Chinese model in Shenzhen. Housing Studies, 25(1), 83100

Wang C. and Yang S. (2015). The Socio-Spatial Structure Transformation in Shanghai: A Dualistic Society and a Dualistic Space. Journal of East China Normal University: Humanities and Social Sciences, 6, 30-37 (In Chinese)

Wang, D. and Li, S.-M., (2004). Housing preferences in a transitional housing system: the case of Beijing, China. Environment and Planning A, 36, 69-87

Wang, W. W., and C. C. Fan. (2012). Migrant workers' integration in urban China: experience in employment, social adaptation, and self-identity. Eurasian Geography and Economics 53 (6), 731-749

Waren W. (2013). Houston's Emerging Exposure between African Americans and Whites: Evidence of Spatial Assimilation or Place Stratification? Population, Space and Place, 19(5), 633-643

Wu J. and Sun B. (2015). Job accessibility and its impact on income: outcomes from Shanghai Metropolitan Area. Geographical Research, 34(9), 744-1754 (in Chinese)

Wu R., Wang Y. and Zhong H. (2012). Spatial distribution of school-age migrants and 
its impact on in Shanghai. Statistical Theory and Practice, 11,21-23 (in Chinese)

Wu, F. (2012). Neighborhood Attachment, Social Participation, and Willingness to Stay in China's Low-Income Communities. Urban Affairs Review, 48 (4), 547570

Wu, F., Zhang F., and Webster, C. (2013). Informality and the development and demolition of urban villages in the Chinese peri-urban area. Urban Studies, 50(10), 1919-1934

Wu, W. (2004) Sources of migrant housing disadvantage in urban China, Environment and Planning A, 36(7), pp. 1285-1304

Wu W. (2008). Migrant settlement and spatial distribution in metropolitan Shanghai, Professional Geographer, 60(1), 101-120

Xie, Y. and Gough, M. (2011). Ethnic enclaves and the earning of immigrants, Demography, 48(4), 1293-1315

Xu, Q., Guan, X. \& Yao, F. (2011). Welfare program participation among rural-tourban migrant workers in China, International Journal of Social Welfare, 20(1), $10-21$

Zhang K. (2015). Uneven spatial distribution of medical services Shanghai. Paper presented at Annual Meeting of Chinese National Planning Conference, Guiyang, 2014 (In Chinese)

Zhang L. (2011). The political economy of informal settlements in post-socialist China: The case of chengzhongcun(s). Geoforum 42(4), 473-483

Zhang L. (2001). Strangers in the City: Reconfigurations of Space, Power, and Social 
Networks within China's Floating Population. Stanford, CT: Stanford University Press

Zhang L, Zhao SXB and Tian JP (2003). Self-help in housing and chengzhongcun in China's urbanization. International Journal of Urban and Regional Research 27(4): 912-937

Zhou, Y., and Ma, L. J. C. (2000). Economic restructuring and suburbanisation in China. Urban Geography, 21(3), 205-236 